\title{
Liquid-phase Hydrogenation of Phenol to Cyclohexanone over Supported Palladium Catalysts
}

\author{
Lihui Fan*, Luyang Zhang, Yanming Shen*, Dongbin Liu, Nasarul Wahab, \\ Md Mahmud Hasan
}

Department of Chemical Engineering, Shenyang University of Chemical Technology, China 110142

Received: $7^{\text {th }}$ March 2016; Revised: $13^{\text {rd }}$ May 2016; Accepted: 7th June 2016

\section{Abstract}

The ZSM-5, $\gamma-\mathrm{Al}_{2} \mathrm{O}_{3}, \mathrm{SiO}_{2}$ and $\mathrm{MgO}$ supported Pd-catalysts were prepared for the phenol hydrogenation to cyclohexanone in liquid-phase. The natures of these catalysts were characterized by XRD, $\mathrm{N}_{2}$ adsorption-desorption analysis, $\mathrm{H}_{2}$-TPR, $\mathrm{CO}_{2}$-TPD and $\mathrm{NH}_{3}$-TPD. The catalytic performance of the supported Pd-catalyst for phenol hydrogenation to cyclohexanone is closely related to nature of the support and the size of $\mathrm{Pd}$ nanoparticles. The $\mathrm{Pd} / \mathrm{MgO}$ catalyst which possesses higher basicity shows higher cyclohexanone selectivity, but lower phenol conversion owing to the lower specific surface area. The $\mathrm{Pd} / \mathrm{SiO}_{2}$ catalyst prepared by precipitation gives higher cyclohexanone selectivity and phenol conversion, due to the moderate amount of Lewis acidic sites, and the smaller size and higher dispersion of $\mathrm{Pd}$ nanoparticles on the surface. Under the reaction temperature of $135{ }^{\circ} \mathrm{C}$ and $\mathrm{H}_{2}$ pressure of $1 \mathrm{MPa}$, after reacting for $3.5 \mathrm{~h}$, the phenol conversion of $71.62 \%$ and the cyclohexanone selectivity of $90.77 \%$ can be obtained over $0.5 \mathrm{wt} \% \mathrm{Pd} / \mathrm{SiO}_{2}$ catalyst. Copyright (c) 2016 BCREC GROUP. All rights reserved

Keywords: cyclohexanone; phenol; hydrogenation; Pd-catalyst; liquid-phase

How to Cite: Fan, L., Zhang, L., Shen, Y., Liu, D., Wahab, N., Hasan, M.M. (2016). Liquid-phase Hydrogenation of Phenol to Cyclohexanone over Supported Palladium Catalysts. Bulletin of Chemical Reaction Engineering \& Catalysis, 11 (3): 354-362 (doi: 10.9767/bcrec.11.3.575.354-362)

Permalink/DOI: http://doi.org/10.9767/bcrec.11.3.575.354-362

\section{Introduction}

Cyclohexanone is a key raw material in the production of both caprolactam for nylon 6 and adipic acid for nylon 66. In industry, cyclohexanone is usually produced via hydrogenation of phenol [1,2]. This route may take place in onestep (direct) fashion or via the formation of cyclohexanol followed by dehydrogenation (twostep process). The one-step and selective hydrogenation of phenol is certainly greener and therefore preferable, but cyclohexanone is

* Corresponding Author.

E-mail: sym6821@sina.com.cn (Y. Shen) rather active and may be easily further hydrogenated to cyclohexanol or other byproducts [3]. To achieve high efficiency in the "one-step" process, the development of a functional catalyst with the special property to control the selective hydrogenation is the key point. Various carriers supported Pd catalysts were developed for phenol hydrogenation, such as $\mathrm{Pd} / \mathrm{MgO}[4$, 5], $\mathrm{Pd} / \mathrm{Al}_{2} \mathrm{O}_{3}[6,7], \mathrm{Pd} / \mathrm{AC}(\mathrm{CNT})$ [8,9], Pd-Ce$\mathrm{B} /$ hydrotalcite $[1,2]$, etc. The nature of the support plays an important role in the activity and selectivity of $\mathrm{Pd}$ catalysts for the hydrogenation of phenol [10]. It is reported that a basic support favours cyclohexanone formation than a acid support, such as $\mathrm{Pd} / \mathrm{MgO}$ provided a 
higher selectivity to cyclohexanone compared to $\mathrm{Pd} / \mathrm{Al}_{2} \mathrm{O}_{3}$ [10]. Pd supported on calcined $\mathrm{Mg} / \mathrm{Al}$ hydrotalcites exhibit high reactivity and selectivity to cyclohexanone and attributed these performance to the presence of strong basic sites $[11,12]$. However, a acid support also can promote this reaction $[7,13,14]$, especially the Lewis acids can activate aromatic rings and in turn improve the phenol conversion and cyclohexanone selectivity [15]. At the same time, the acid sites also enrich the electron density of $\mathrm{Pd}$, enhance the desorption of phenoxy species and inhibit further hydrogenation of the intermediate product $[8,14]$. These contradictory results arouse us to investigate the catalytic performance for phenol hydrogenation on different supported $\mathrm{Pd}$ catalysts. $\mathrm{ZSM}-5, \mathrm{SiO}_{2}$ and $\mathrm{Al}_{2} \mathrm{O}_{3}$ are commonly used as the acidic supports and $\mathrm{MgO}$ is used as the basic support in catalytic reactions. In this work, we prepared Pd/ZSM-5, $\mathrm{Pd} / \mathrm{SiO}_{2}, \mathrm{Pd} / \mathrm{Al}_{2} \mathrm{O}_{3}$, and $\mathrm{Pd} / \mathrm{MgO}$ catalysts with a $0.5 \mathrm{wt} \% \mathrm{Pd}$ loading relative to the mass of the support, aiming at the investigation of the the effects of the support properties on the phenol conversion and cyclohexanone selectivity.

\section{Materials and Method}

\subsection{Materials}

ZSM-5 and $\gamma-\mathrm{Al}_{2} \mathrm{O}_{3}$ was purchased from the Catalyst Plant of Nankai University, China. The acidic silica sol (containing about 25 wt\% $\mathrm{SiO}_{2}$ ) was purchased from Sinopharm Chemical Reagent Co, Ltd, China. $\mathrm{MgO}$ was prepared by calcination of $\mathrm{Mg}(\mathrm{OH})_{2}$ at $600{ }^{\circ} \mathrm{C}$ for $4 \mathrm{~h}$. Before impregnation these supporters were calcined at $550{ }^{\circ} \mathrm{C}$ for $4 \mathrm{~h}$ except silica sol.

\subsection{Catalyst preparation}

Pd-catalysts with a $0.5 \mathrm{wt} \% \mathrm{Pd}$ loading relative to the mass of the support were prepared by incipient-wetness impregnation method. This general procedure was slightly modified, the volume of the solution being twice the one of the porous volume of the supports in order to impregnate both internal and external surfaces. For Pd/ZSM-5 and $\mathrm{Pd} / \mathrm{Al}_{2} \mathrm{O}_{3}$ catalysts, before impregnation, the supports ZSM-5 and $\mathrm{Al}_{2} \mathrm{O}_{3}$ were calcined at $450{ }^{\circ} \mathrm{C}$. For $\mathrm{Pd} / \mathrm{MgO}$ catalyst, the support $\mathrm{MgO}$ was prepared by the following steps: the $\mathrm{pH}$ of the $1 \mathrm{M} \mathrm{Mg}\left(\mathrm{NO}_{3}\right)_{2}$ solution was adjusted to about 10 by adding 0.1 M ammonia water, forming $\mathrm{Mg}(\mathrm{OH})_{2}$. After filtration and drying, the resulted $\mathrm{Mg}(\mathrm{OH})_{2}$ was converted to $\mathrm{MgO}$ support by calcination at 550 ${ }^{\circ} \mathrm{C}$ in an oven for $4 \mathrm{~h}$. The $62.5 \mathrm{mg}$ of $\mathrm{Pd}\left(\mathrm{NO}_{3}\right)_{2} \cdot 2 \mathrm{H}_{2} \mathrm{O}$ were dissolved in the calculated volume of distilled water and several drops of $\mathrm{HNO}_{3}$ were added until $\mathrm{Pd}\left(\mathrm{NO}_{3}\right)_{2}$ were completely dissolved. Then $5 \mathrm{~g}$ of the above calcined supports were put into the above solution for impregnation. The resulted suspensions were stirred at room temperature for $12 \mathrm{~h}$, then were evaporated at $85^{\circ} \mathrm{C}$ till the solutions become dry. The resulting powders were dried at $80{ }^{\circ} \mathrm{C}$ for $12 \mathrm{~h}$ and calcined at 550 ${ }^{\circ} \mathrm{C}$ in an oven for $4 \mathrm{~h}$, finally $\mathrm{Pd} / \mathrm{ZSM}-5$, $\mathrm{Pd} / \mathrm{Al}_{2} \mathrm{O}_{3}$ and $\mathrm{Pd} / \mathrm{MgO}$ catalysts were obtained. In case of $\mathrm{Pd} / \mathrm{SiO}_{2}$ catalyst, it was prepared using acidic silica sol (containing $25 \mathrm{wt} \% \mathrm{SiO}_{2}$ ) as the precursor of $\mathrm{SiO}_{2} .62 .5 \mathrm{mg}$ of $\mathrm{Pd}\left(\mathrm{NO}_{3}\right)_{2} \cdot 2 \mathrm{H}_{2} \mathrm{O}$ were dissolved in $10 \mathrm{~mL}$ of distilled water and several drops of $\mathrm{HNO}_{3}$ were added until $\operatorname{Pd}\left(\mathrm{NO}_{3}\right)_{2}$ were completely dissolved, then the solution was put into $20 \mathrm{~g}$ of the acidic silica sol under stirring. The resulted solution were stirred at room temperature for $12 \mathrm{~h}$. After drying and calcination as described for other catalysts, the $\mathrm{Pd} / \mathrm{SiO}_{2}$ catalyst was obtained.

The catalysts were reduced by hydrazine hydrate before using for the activity test. The hydrazine hydrate was slowly added into the suspension of catalysts and distilled water under stirring at room temperature. The hydrazine hydrate/Pd molar ratio was 1.5 . The reduction process was last for $4 \mathrm{~h}$.

\subsection{Catalyst characterization}

X-ray powder diffraction (XRD) patterns were recorded on a D08 Advance powder diffractometer (Bruker) using a $\mathrm{Cu}-\mathrm{Ka}$ radiation source operated at $40 \mathrm{kV}$ and $200 \mathrm{~mA}$ in the $2 \theta$ range from 5 to $70^{\circ}$. The BET specific surface area and pore size distributions of the samples were measured by the Versorb 2800P surface area and pore size analyzer (Gold APP Instrument Corporation China). Temperature programmed reduction (TPR) of the catalysts was carried out in a quartz tube reactor with a mixture of $\mathrm{H}_{2}$ and $\mathrm{N}_{2}\left(\mathrm{H}_{2} / \mathrm{N}_{2}=5 / 95\right)$ flowing at $30 \mathrm{~cm}^{3} / \mathrm{min}$. $50 \mathrm{mg}$ of the catalyst was heated from room temperature to $800{ }^{\circ} \mathrm{C}$ at the rate of $10{ }^{\circ} \mathrm{C} / \mathrm{min}$. The water produced in the reaction was removed by driving the exit stream through a tube containing silica gel and 5A zeolite. The dried outlet gas was analyzed by a thermal conductivity detector (TCD) and the $\mathrm{H}_{2}$ content was recorded continuously. Temperature programmed desorption (TPD) of $\mathrm{CO}_{2}$ and $\mathrm{NH}_{3}$ were carried out on $200 \mathrm{mg}$ of the catalyst sample under helium as the carrier gas (flow rate $30 \mathrm{~cm}^{3} / \mathrm{min}$ ). Prior to $\mathrm{CO}_{2}$ and $\mathrm{NH}_{3}$ adsorption, all catalysts were heated up to 450 
${ }^{\circ} \mathrm{C}$. Then, $\mathrm{CO}_{2}$ and $\mathrm{NH}_{3}$ were introduced into the tube at room temperature for adsorption of 30 min and the desorption of $\mathrm{CO}_{2}$ and $\mathrm{NH}_{3}$ was invoked by heating $\left(10{ }^{\circ} \mathrm{C} / \mathrm{min}\right)$ in helium up to the final temperature of $800{ }^{\circ} \mathrm{C}$. The outlet gas was analyzed by a TCD and the $\mathrm{CO}_{2}$ and $\mathrm{NH}_{3}$ content was recorded continuously.

\subsection{Catalytic activity test}

Catalytic activity was tested in a $100 \mathrm{ml}$ autoclave. The $1 \mathrm{~g}$ of catalysts and $20 \mathrm{ml}$ raw materials (ethanol phenol mass ratio 1:4) were put into the autoclave. The sealed autoclave was purged 2 times with $\mathrm{N}_{2}$ in order to remove air, and purged 5 times with $\mathrm{H}_{2}$ in order to remove $\mathrm{N}_{2}$ completely. The reaction was carried out at $135{ }^{\circ} \mathrm{C}$ and $1.0 \mathrm{MPa}$ under the stirring speed of $800 \mathrm{rpm}$. During reaction, samples were withdrawn from the reaction mixture at intervals and were analyzed by gas chromatography (SP-2100, Beijing Rayleigh analytic Co, Ltd) equipped with a capillary column (AT FFAP $30 \mathrm{~m} \times 0.32 \mathrm{~mm} \times 0.5 \mu \mathrm{m}$ ) and a flame ionization detector. The phenol conversion $\left(X_{A}\right)$ and the of the products selectivity $\left(S_{i}\right)$ were defined as follows [14]:

Phenol conversion $\left(X_{A}\right)=\left(\right.$ phenol $_{\text {added-mol }}-$ phenol remain-mol $/$ phenol added-mol

Product $i$ selectivity $\left(S_{i}\right)=$ Product $i_{\text {formed-mol }} /$ (phenol added-mol - phenol ${ }_{\text {remain-mol }}$ )

\section{Results and Discussion}

\subsection{Catalyst characterization}

The surface area, pore volume and pore diameter distribution of the obtained catalysts are determined by the $\mathrm{N}_{2}$ adsorption-desorption method. Figure 1 shows the $\mathrm{N}_{2}$ adsorptiondesorption isotherms and pore size distribution of catalysts.

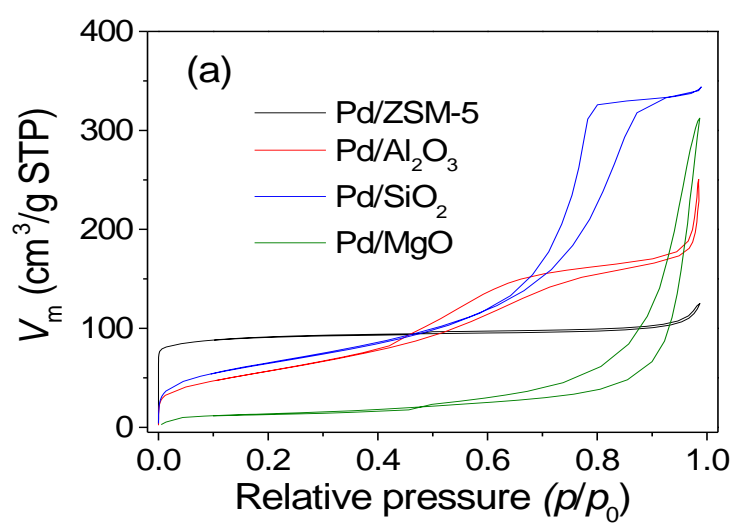

Pd/ZSM-5 isotherm exhibits nearly identical isotherm, which belongs to the type I isotherms (IUPAC), suggesting the microporous structure of Pd/ZSM-5 catalyst [16]. The pore size distribution curve in Figure 1(b) indicates the Pd/ZSM-5 possesses narrow pore size distribution and its average pore size is centered $0.43 \mathrm{~nm}$. The BET specific surface area and mesopore volume determined by the HK model for Pd/ZSM-5 sample are measured to be $305.2 \mathrm{~m}^{2} / \mathrm{g}$ and $0.19 \mathrm{~cm}^{3} / \mathrm{g}$, respectively.

The $\mathrm{Pd} / \mathrm{Al}_{2} \mathrm{O}_{3}, \quad \mathrm{Pd} / \mathrm{SiO}_{2}$ and $\mathrm{Pd} / \mathrm{MgO}$ catalysts provide the type IV isotherms with distinct hysteresis loops, indicating they possess mesopore structure. The BET specific surface area and mesopore volumes calculated by the BJH model are listed in Table 1. The specific surface area decreases in the following order: $\mathrm{Pd} / \mathrm{ZSM}-5>\mathrm{Pd} / \mathrm{SiO}_{2}>\mathrm{Pd} / \mathrm{Al}_{2} \mathrm{O}_{3}>$ $\mathrm{Pd} / \mathrm{MgO}$.

Figure 2 shows the XRD patterns of $\mathrm{Pd}$ catalysts after reduction. It is noteworthy that only reflections from the supports were observed. There is no detectable palladium phase presents in the XRD patterns, due to very low $\mathrm{Pd}$ loadings [13]. When the $\mathrm{Pd} / \mathrm{MgO}$ catalyst was reduced by hydrazine hydrate in aqueous solution, the main phase was $\mathrm{Mg}(\mathrm{OH})_{2}$, which is formed from $\mathrm{MgO}$ and $\mathrm{H}_{2} \mathrm{O}$ during the aqueous reduction [5].

TEM images of the four catalysts are shown in Figure 3. In case of the $\mathrm{Pd} / \mathrm{Al}_{2} \mathrm{O}_{3}, \mathrm{Pd} / \mathrm{ZSM}-5$ and $\mathrm{Pd} / \mathrm{MgO}$, which are prepared by impregnation, $\mathrm{Pd}$ nanoparticles agglomerated to clusters. For $\mathrm{Pd} / \mathrm{SiO}_{2}$ catalyst, which is prepared by precipitation, small sized $\mathrm{Pd}$

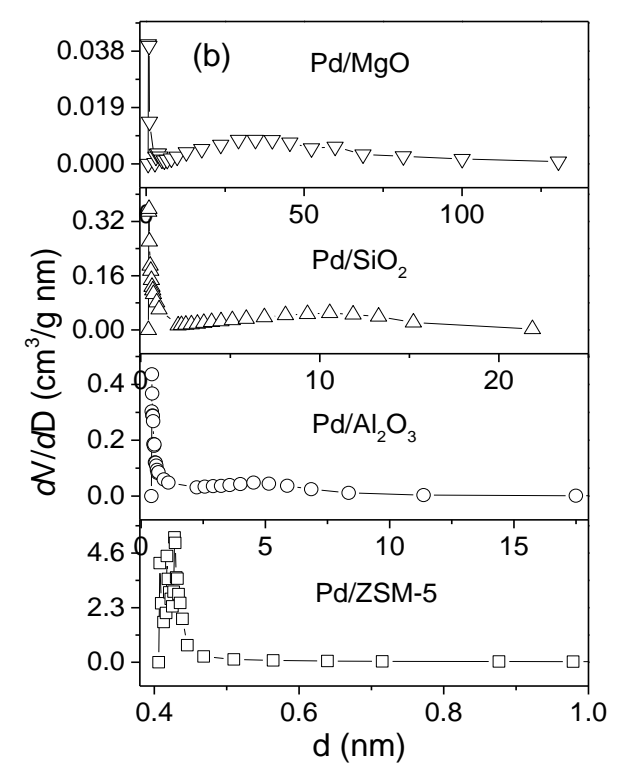

Figure 1. Adsorption desorption isotherms (a) and pore distribution curves (b) of catalysts 
nanoparticles well disperse on the surface of $\mathrm{SiO}_{2}$.

The TPR profiles, obtained from the TCD output, are shown in Figure 4, where hydrogen consumption appears as a positive peak and hydrogen desorption as a negative peak. The low-temperature negative peak ( $T_{\max }$ below 105 $\left.{ }^{\circ} \mathrm{C}\right)$ that appears in TPR profiles for the four catalysts in Figure 4 is entirely reproducible and is diagnostic of a metallic palladium component during the calcination step. This can be attributed to $\mathrm{H}_{2}$ release resulting from the decomposition of $\mathrm{Pd}$ hydride, which is formed by $\mathrm{H}_{2}$ absorption [5]. This result shows that $\mathrm{Pd}$ component exists in the samples though it is not detected by XRD. The $\mathrm{Pd} / \gamma$ $\mathrm{Al}_{2} \mathrm{O}_{3}$ and $\mathrm{Pd} / \mathrm{ZSM}-5$ catalysts provide a second negative peak around $200{ }^{\circ} \mathrm{C}$, which is originated from the hydrogen spillover on the supports [17]. The reduction of $\mathrm{PdO}$ to $\mathrm{Pd}{ }^{\circ}$ can be conducted at room temperature $[17,18]$, and this reaction may well occur concomitantly with hydrogen consumption. The positive peak centered at temperature of $430{ }^{\circ} \mathrm{C}$ in the TPR curve of the $\mathrm{Pd} / \mathrm{ZSM}-5$ catalyst is originated from the reduction of $\mathrm{Pd}$ oxides which interact strongly with the ZSM-5 support. This strong interaction was probably formed during the calcination of as-synthesized zeolite-supported $\mathrm{Pd}$ catalyst, $\mathrm{Pd}^{2+}$ ions as the main species will be stabilized in certain sites of a zeolite channel or external surface. Zeolitic protons as the Brönsted sites can enhance the interaction between the metal and support by chemically anchoring small $\mathrm{Pd}$ species, therefore making them more difficult to be reduced [19]. This strong interaction also was observed on $\mathrm{Pd} / \mathrm{Al}_{2} \mathrm{O}_{3}$ catalyst, by the evidence of a broad positive peak ranging from $300{ }^{\circ} \mathrm{C}$ to $700{ }^{\circ} \mathrm{C}$ presented in the TPR curve. Two distinct positive peaks at temperature above $400{ }^{\circ} \mathrm{C}$ are found in the TPR profile of $\mathrm{Pd} / \mathrm{MgO}$ catalyst. These peaks are attributed to the formation of $\mathrm{Mg}_{\mathrm{s}} \mathrm{H}$ and $\mathrm{Mg}_{\mathrm{s}} \mathrm{OH}$ species on the $\mathrm{MgO}$ under $\mathrm{H}_{2}$ [5], resulting in the consumption of hydrogen. There are no distinct positive peaks in the TPR

Table 1. The physical properties of catalystsa

\begin{tabular}{cccc}
\hline Samples & Specific surface area $\left(\mathrm{m}^{2} / \mathrm{g}\right)$ & Pore volume $\left(\mathrm{cm}^{3} / \mathrm{g}\right)$ & Pore diameter $(\mathrm{nm})$ \\
\hline $\mathrm{Pd} / \mathrm{ZSM}-5$ & 305.15 & 0.13 & 0.43 \\
$\mathrm{Pd} / \mathrm{Al}_{2} \mathrm{O}_{3}$ & 209.68 & 0.39 & 7.23 \\
$\mathrm{Pd} / \mathrm{SiO}_{2}$ & 237.93 & 0.53 & 8.37 \\
$\mathrm{Pd} / \mathrm{MgO}$ & 48.92 & 0.48 & 32.60 \\
\hline
\end{tabular}

a The pore volume and pore diameter was calculated by the HK model for Pd/ZSM-5, while by the BJH model for other catalysts.

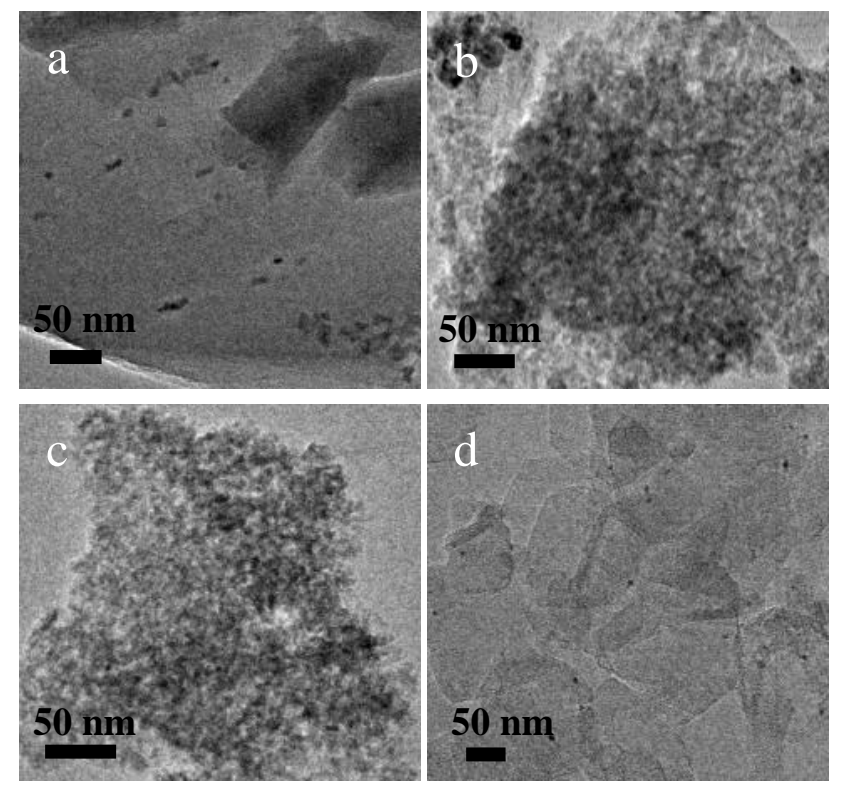

Figure 2. TEM images of catalysts: (a) Pd/ZSM-5, (b) $\mathrm{Pd} / \mathrm{Al}_{2} \mathrm{O}_{3}$, (c) $\mathrm{Pd} / \mathrm{MgO}$, (d) $\mathrm{Pd} / \mathrm{SiO}_{2}$

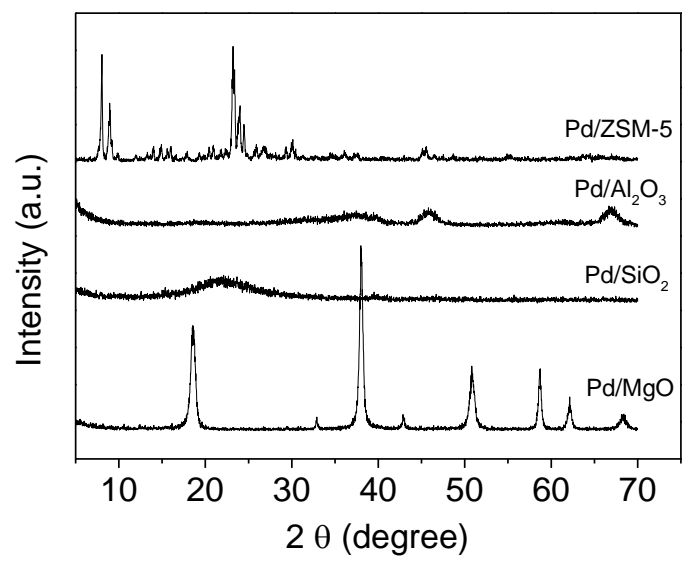

Figure 3. XRD patterns of catalysts after reduction 
profiles of $\mathrm{Pd} / \mathrm{SiO}_{2}$, illustrating that the $\mathrm{Pd}$ oxides/hybrids were completely reduced at low temperature, owing to the small size and higher dispersion of $\mathrm{Pd}$ on the surface of $\mathrm{SiO}_{2}$.

The acidic and basic properties were determined by $\mathrm{NH}_{3}$-TPD and $\mathrm{CO}_{2}$-TPD, respectively, as shown in Figure 5. The acidic sites can be classified as weak $\left(150-250{ }^{\circ} \mathrm{C}\right)$, medium $\left(250-350{ }^{\circ} \mathrm{C}\right)$ and strong $\left(350-450{ }^{\circ} \mathrm{C}\right)$ on the basis of the desorption temperature [20]. It can be assumed that the $\mathrm{NH}_{3}$ desorption in the low-temperature (LT) range is attributed to the presence of physisorbed $\mathrm{NH}_{3}$ species and/or ammonia adsorbed on very weak Brønsted acid sites, whereas the high-temperature (HT) maximum corresponds to ammonia leaving stronger Lewis sites [21].

$\mathrm{NH}_{3}$-TPD profile of Pd/ZSM-5 shows two desorption peaks, indicating the existence of two acid sites. The low-temperature peak is found between $138{ }^{\circ} \mathrm{C}$ and $300{ }^{\circ} \mathrm{C}$ and is attributed to desorption of weakly bound ammonia. The high-temperature desorption peak is found above $400{ }^{\circ} \mathrm{C}$ and is attributed to desorption of ammonia from the strong Brønsted (B) and Lewis (L) acid sites, which are related to framework $\mathrm{Al}$ atoms charge

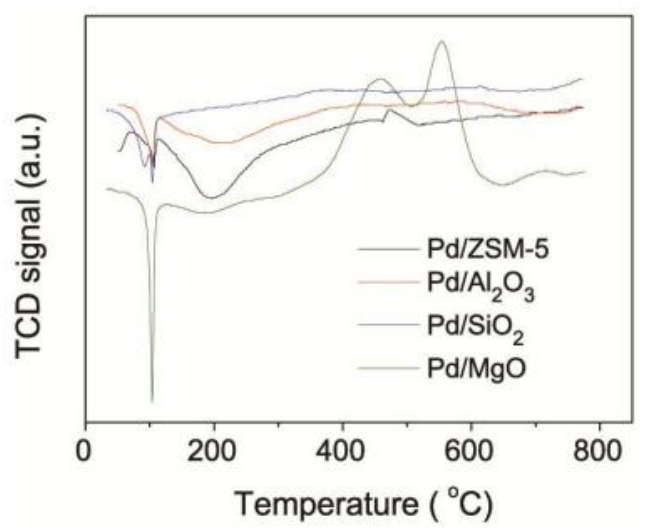

Figure 4. TPR profiles of Pd catalysts

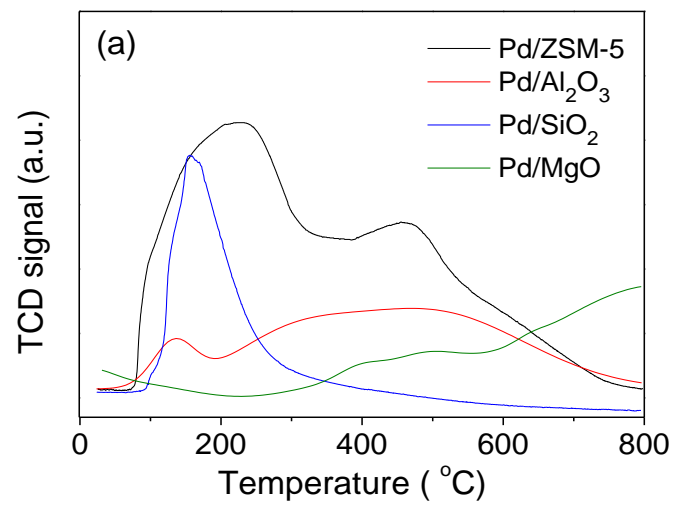

compensated by acidic protons and to extraframework $\mathrm{Al}$ atoms, respectively [22,23]. These strong Brønsted and Lewis acid sites are believed to be the main catalytic centers.

The $\mathrm{NH}_{3}$-TPD curve of $\mathrm{Pd} / \mathrm{SiO}_{2}$ presents a strong low-temperature peak, showing that the weak Brønsted acid sites mainly exist in the $\mathrm{Pd} / \mathrm{SiO}_{2}$ catalyst. The $\mathrm{NH}_{3}-\mathrm{TPD}$ curve of $\mathrm{Pd} / \gamma$ $\mathrm{Al}_{2} \mathrm{O}_{3}$ provides a $\mathrm{LT}$ desorption peak and a broad HT desorption peak, indicating that both $\mathrm{B}$ and $\mathrm{L}$ acid sites exist in $\mathrm{Pd} / \gamma-\mathrm{Al}_{2} \mathrm{O}_{3}$ catalyst. While there is no distinct $\mathrm{NH}_{3}$ desorption peak in the $\mathrm{NH}_{3}$-TPD curve of $\mathrm{Pd} / \mathrm{MgO}$, suggesting that no/less acid sites exist in $\mathrm{Pd} / \mathrm{MgO}$ catalyst. Based on the results of $\mathrm{NH}_{3}$-TPD, the order of acidity for the catalysts can be described as $\mathrm{Pd} / \mathrm{ZSM}-5>\mathrm{Pd} / \gamma-\mathrm{Al}_{2} \mathrm{O}_{3}>\mathrm{Pd} / \mathrm{SiO}_{2}>\mathrm{Pd} / \mathrm{MgO}$.

In $\mathrm{CO}_{2}$-TPD, the low-temperature desorption peak corresponds to $\mathrm{CO}_{2}$ adsorbed on the weak basic sites (OH-groups) while the peak in the intermediate temperature range and at high temperature represent $\mathrm{CO}_{2}$ adsorptions on the medium strength $\left(\mathrm{O}^{2-}\right.$ in metal and $\mathrm{O}^{2-}$ pairs) and strong strength basic $\left(\mathrm{O}^{2-}\right.$ ions in low coordination) sites, respectively. The three kinds of bases exhibit weak, medium and strong basicity, which corresponds to the $\mathrm{CO}_{2}$ desorption temperature in the range of $25-200{ }^{\circ} \mathrm{C}, 200-400{ }^{\circ} \mathrm{C}$ and above $400{ }^{\circ} \mathrm{C}$, respectively [24]. The $\mathrm{CO}_{2}$-TPD curve of $\mathrm{Pd} / \mathrm{MgO}$ displays three distinct desorption peaks, indicating that a variety of basic sites with different strengths are presented on the surface of the $\mathrm{MgO}$ samples. The $\mathrm{CO}_{2}$-TPD curve of $\mathrm{Pd} / \gamma-\mathrm{Al}_{2} \mathrm{O}_{3}$ shows a comparable strong desorption at low-temperature of $120{ }^{\circ} \mathrm{C}$ and a weak and broad high-temperature ranging from 380 to $700{ }^{\circ} \mathrm{C}$. Both Pd/ZSM-5 and $\mathrm{Pd} / \mathrm{SiO}_{2}$ catalyst only presents a weak and broad high-temperature peak. Thus, in terms of the strength and number, the basicity of the four catalysts can be arranged in the following

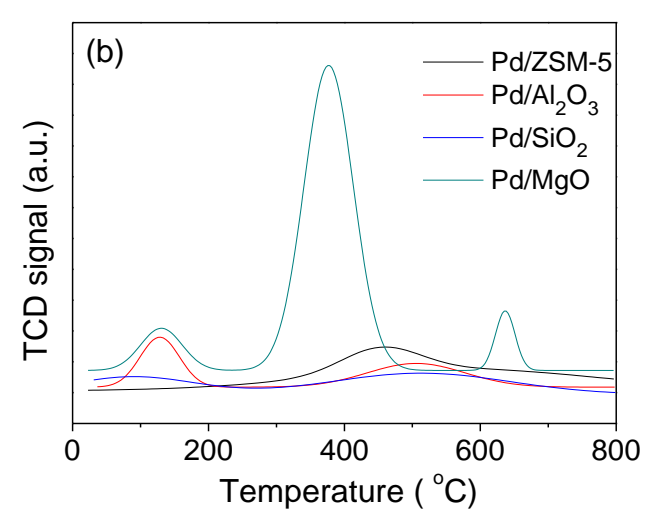

Figure 5. $\mathrm{NH}_{3}$-TPD (a) and $\mathrm{CO}_{2}$-TPD (b) curves of catalysts 
order: $\mathrm{Pd} / \mathrm{MgO}>\mathrm{Pd} / \gamma-\mathrm{Al}_{2} \mathrm{O}_{3}>\mathrm{Pd} /$ ZSM-5 $>$ $\mathrm{Pd} / \mathrm{SiO}_{2}$.

\subsection{Catalytic activity test}

Liquid-phase phenol hydrogenation was carried out on these catalysts, the results are listed in Table 2. It can be observed that the selectivity of cyclohexanone decrease in the order: $\mathrm{Pd} / \mathrm{MgO}>\mathrm{Pd} / \mathrm{SiO}_{2}>\mathrm{Pd} / \mathrm{ZSM}-5>\mathrm{Pd} / \mathrm{Y}^{-}$ $\mathrm{Al}_{2} \mathrm{O}_{3}$.

The catalytic activity is usually influenced by the properties of a catalyst, such as the specific surface area, pore size, the metal loading, acidic and basic sites, etc. It is reported that, for phenol hydrogenation to cyclohexanol, the higher the basicity (or the lower the acidity) of the catalyst, the higher the activity and the selectivity to cyclohexanone [6, $10,12,25]$. Among these four catalysts in this work, $\mathrm{Pd} / \mathrm{MgO}$ shows the highest basicity and the highest cyclohexanone selectivity. Pd/ZSM5 and $\mathrm{Pd} / \gamma-\mathrm{Al}_{2} \mathrm{O}_{3}$ have lower basic sites, thus provide lower phenol conversion and cyclohexanone selectivity. The $\mathrm{Pd} / \gamma-\mathrm{Al}_{2} \mathrm{O}_{3}$ shows higher basicity than that of Pd/ZSM-5, but the cyclohexanone selectivity shows the opposite result. $\mathrm{NH}_{3}-\mathrm{TPD}$ results show that Pd/ZSM-5 possesses more acidic sites, especially the medium and strong acid sites which are belonged to strong $\mathrm{B}$ and $\mathrm{L}$ acids, than $\mathrm{Pd} / \gamma-\mathrm{Al}_{2} \mathrm{O}_{3}$. Jiang et al. reported that the Lewis acid could suppress the hydrogenation of cyclohexanone to cyclohexanol [15]. Thus the higher cyclohexanone selectivity observed on the Pd/ZSM-5 is attributed to the more Lewis acidic sites on the surface. The more acidic sites on the surface also resulted in the formation of cyclohexane, as indicated in Table 2.

The exception can be found in $\mathrm{Pd} / \mathrm{SiO}_{2}$ catalyst, which possess the lowest basicity among the four catalysts but shows the relative higher phenol conversion and cyclohexanone selectivity. This may be explained by the higher dispersion of $\mathrm{Pd}$ on the $\mathrm{SiO}_{2}$ surface, that is, the highly dispersed Pd nanoparticles significantly improve the performance of the catalyst [26]. In this work, $\mathrm{Pd} / \mathrm{SiO}_{2}$ catalyst was prepared by precipitation, which is different from impregnation used in the preparation for other catalysts. It is common acceptable that precipitation method results in higher dispersion of metal active sites on the surface of the support than impregnation. Therefore, the higher dispersion of $\mathrm{Pd}$ on the surface of $\mathrm{Pd} / \mathrm{SiO}_{2}$ resulted in the higher selectivity.

The phenol conversion, as shown in Table 2, decreases in the order: $\mathrm{Pd} / \mathrm{SiO}_{2}>\mathrm{Pd} / \mathrm{ZSM}-5>$ $\mathrm{Pd} / \gamma-\mathrm{Al}_{2} \mathrm{O}_{3}>\mathrm{Pd} / \mathrm{MgO}$. Higher phenol conversion was obtained on $\mathrm{Pd} / \mathrm{SiO}_{2}$ catalyst. This is attributed to the higher dispersion of $\mathrm{Pd}$ nanoparticles on the surface of $\mathrm{SiO}_{2}$. In the case of $\mathrm{Pd} / \mathrm{ZSM}-5, \mathrm{Pd} / \gamma-\mathrm{Al}_{2} \mathrm{O}_{3}$ and $\mathrm{Pd} / \mathrm{MgO}$ catalysts, the lower phenol conversion is originated from the lower dispersion and the bigger $\mathrm{Pd}$ nanoparticles formed by agglomeration. In principle, the specific surface area and the nanoparticle size of a heterogeneous catalyst can have an important effect on the catalytic activity. As shown in Table 1, the specific surface area for Pd/ZSM-5, $\mathrm{Pd} / \gamma-\mathrm{Al}_{2} \mathrm{O}_{3}$ and $\mathrm{Pd} / \mathrm{MgO}$ catalysts decreases in the order: $\mathrm{Pd} / \mathrm{ZSM}-5>\mathrm{Pd} / \gamma-\mathrm{Al}_{2} \mathrm{O}_{3}>\mathrm{Pd} / \mathrm{MgO}$, resulting the phenol conversion on these catalysts follows this order.

\subsection{Mechanism}

As shown in Figure 6, the hydrogenation of phenol produces cyclohexenol (step I), as an intermediate product, that subsequently gives cyclohexanol (via hydrogenation, step III), or cyclohexanone (via isomerization, step II) which can be converted into cyclohexanol via hydrogenation (step IV). The cyclohexanol can further dehydrate to cyclohexane (step V) [2, 27]. The reported results indicate that phenol is adsorbed and activated on the support while $\mathrm{H}_{2}$ is activated on the $\mathrm{Pd}$ and produces the hydrogenation of the adsorbed phenol. However, the hydrogenation of phenol yields cyclohexanone and cyclohexanol depending that the adsorption of phenol occurs through the hydroxyl or the aromatic ring, respectively

Table 2. Catalytic performances of catalysts

\begin{tabular}{ccccc}
\hline \multirow{2}{*}{ Samples } & \multirow{2}{*}{ Conversion (\%) } & \multicolumn{3}{c}{ Selectivity (\%) } \\
\cline { 3 - 5 } & & cyclohexanone & cyclohexanol & cyclohexane \\
\hline $\mathrm{Pd} / \mathrm{ZSM}-5$ & 63.54 & 76.31 & 16.19 & 7.50 \\
$\mathrm{Pd} / \mathrm{Al}_{2} \mathrm{O}_{3}$ & 54.58 & 68.31 & 30.75 & 0.93 \\
$\mathrm{Pd} / \mathrm{SiO}_{2}$ & 71.62 & 90.77 & 9.23 & 0 \\
$\mathrm{Pd} / \mathrm{MgO}$ & 46.82 & 91.33 & 8.67 & 0 \\
\hline
\end{tabular}


[27]. The phenol adsorbed in a non-planar fashion over basic sites gives rise to cyclohexanone while that adsorbed on acidic sites in the co-planar fashion leads to the formation of cyclohexanol and cyclohexane [28].

For the reactions catalyzed by the reduced $\mathrm{Pd} / \mathrm{MgO}$, phenol molecules may interact relatively strongly with the surface (through hydrogen bonding) to result in non-planar adsorption. The benzene ring of phenol may then be partially hydrogenated to the cyclohexenol, which can rapidly isomerize to give cyclohexanone. Since cyclohexanone interacts weakly to the surface, it leaves the catalytic site quickly and is replaced by a more strongly binding phenol molecule, avoiding further hydrogenation to cyclohexanol. But the lower specific surface area limits the activity of $\mathrm{Pd} / \mathrm{MgO}$, resulting the lower phenol conversion.

In the case of phenol hydrogenation on $\mathrm{Pd}$ catalysts supported on the acidic supports, $\mathrm{Pd} / \mathrm{ZSM}-5, \mathrm{Pd} / \gamma-\mathrm{Al}_{2} \mathrm{O}_{3}$ and $\mathrm{Pd} / \mathrm{SiO}_{2}$, in a first step, a co-planar adsorption orientation of phenol on the supports is considered. Then the aromatic ring of phenol will interact with $\mathrm{Pd}$ through the formation of $\Pi$-complex [27]. In a second step, the benzene ring is partially hydrogenated to cyclohexenol that quickly isomerizes to the cyclohexanone. The inhibition of the cyclohexanone hydrogenation is inhibited in presence of Lewis acid sites [15]. However, the strong Lewis acidic sites can make the phenol interact strongly with the supports, as a result cyclohexanone further hydrogenates to cyclohexanol and cyclohexane. Pd/ZSM-5 and $\mathrm{Pd} / \gamma-\mathrm{Al}_{2} \mathrm{O}_{3}$ presented more Lewis acidic sites, as a result the main product cyclohexanone converted to cyclohexanol and reduced the cyclohexanone selectivity, while $\mathrm{Pd} / \mathrm{SiO}_{2}$ catalyst possessed less Lewis acidic sites, thus higher cyclohexanone selectivity was obtained. Moreover, the size and the dispersion of $\mathrm{Pd}$ on the support surface also affacted the catalytic

Figure 6. The reaction steps for the hydrogenation of phenol activity. The smaller size and higher dispersion of $\mathrm{Pd}$ benefit the formation of the $\Pi$-complex between benzene ring of phenol and Pd. Here, $\mathrm{Pd} / \mathrm{SiO}_{2}$ prepared by precipitation is considered that has smaller size and higher dispersion of $\mathrm{Pd}$ than $\mathrm{Pd} / \mathrm{ZSM}-5$ and $\mathrm{Pd} / \gamma-\mathrm{Al}_{2} \mathrm{O}_{3}$ which were prepared by impregnation, thus $\mathrm{Pd} / \mathrm{SiO}_{2}$ provided higher activity and cyclohexanone selectivity.

\section{Conclusions}

Based on the results, it is can be seen that the catalytic performance of a supported Pdcatalyst for phenol hydrogenation to cyclohexanone is closely related to nature of the support and the size and dispersion of Pd nanoparticles. Higher basicity is beneficial to the nonplanar adsorption of phenol on the surfaces of the support, in turn to the formation of cyclohexanone. Moderate amount of Lewis acidic sites can improve the cyclohexanone selectivity. The smaller size and higher dispersion of Pd promote the formation of the ח-complex between benzene ring of phenol and $\mathrm{Pd}$ nanoparticles, and finally gives rise to the fast and selective hydrogenation to cyclohexanone. Therefore, the phenol conversion and cyclohexanone selectivity are expected to be improved by the promotion of the basicity and the preparation method for the catalyst.

\section{Acknowledgment}

This work was financially supported by the Scientific Project of Education Deapartment of Liaoning Province, China (LS 2014169).

\section{References}

[1] Jianliang, L., Hui, L., Hexing, L. (2007). Liquid-phase selective hydrogenation of phenol to cyclohexanone over Pd-Ce-B/hydrotalcite catalyst. Chinese Journal of Catalysis 28(4): 312-316.

[2] Li, H., Liu, J., Li, H. (2008). Liquid-phase selective hydrogenation of phenol to cyclohexanone over the Ce-doped Pd-B amorphous alloy catalyst. Materials Letters 62(2): 297-300.

[3] Lin, C.-J., Huang, S.-H., Lai, N.-C., Yang, C.M. (2015). Efficient Room-Temperature Aqueous-Phase Hydrogenation of Phenol to Cyclohexanone Catalyzed by Pd Nanoparticles Supported on Mesoporous MMT-1 Silica with Unevenly Distributed Functionalities. ACS Catalysis 5(7): 4121-4129.

[4] Galvagno, S., Donato, A., Neri, G., Pietropaolo, R. (1991). Hydrogenation of phenol to cyclohexanone over $\mathrm{Pd} / \mathrm{MgO}$. Journal of 
Chemical Technology and Biotechnology 51(2): 145-153.

[5] Claus, P., Berndt, H., Mohr, C., Radnik, J., Shin, E.-J., Keane, M. A. (2000). Pd/MgO: catalyst characterization and phenol hydrogenation activity. Journal of Catalysis 192(1): 88-97.

[6] Scire, S., Crisafulli, C., Maggiore, R., Minicò, S., Galvagno, S. (1998). Effect of the acidbase properties of $\mathrm{Pd}-\mathrm{Ca} / \mathrm{Al}_{2} \mathrm{O}_{3}$ catalysts on the selective hydrogenation of phenol to cyclohexanone: FT-IR and TPD characterization. Applied Surface Science 136(4): 311-320.

[7] Xiang, Y.-z., Kong, L.-n., Lu, C.-s., Ma, L., Li, X.-n. (2010). Lanthanum-promoted $\mathrm{Pd} / \mathrm{Al}_{2} \mathrm{O}_{3}$ catalysts for liquid phase in situ hydrogenation of phenol to cyclohexanone. Reaction Kinetics, Mechanisms and Catalysis 100(1): 227235 .

[8] Watanabe, S., Arunajatesan, V. (2010). Influence of acid modification on selective phenol hydrogenation over $\mathrm{Pd} /$ activated carbon catalysts. Topics in Catalysis 53(15-18): 11501152.

[9] Xiang, Y., Kong, L., Xie, P., Xu, T., Wang, J., Li, X. (2014). Carbon Nanotubes and Activated Carbons Supported Catalysts for Phenol in Situ Hydrogenation: Hydrophobic/Hydrophilic Effect. Industrial \& Engineering Chemistry Research 53(6): 2197-2203.

[10] Neri, G., Visco, A., Donato, A., Milone, C., Malentacchi, M., Gubitosa, G. (1994). Hydrogenation of phenol to cyclohexanone over palladium and alkali-doped palladium catalysts. Applied Catalysis A: General 110(1): 49-59.

[11] Narayanan, S., Krishna, K. (1996). Highly active hydrotalcite supported palladium catalyst for selective synthesis of cyclohexanone from phenol. Applied Catalysis A: General 147(2): L253-L258.

[12] Chen, Y., Liaw, C., Lee, L. (1999). Selective hydrogenation of phenol to cyclohexanone over palladium supported on calcined $\mathrm{Mg} / \mathrm{Al}$ hydrotalcite. Applied Catalysis A: General 177(1): 1-8.

[13] Cheng, L., Dai, Q., Li, H., Wang, X. (2014). Highly selective hydrogenation of phenol and derivatives over $\mathrm{Pd}$ catalysts supported on $\mathrm{SiO}_{2}$ and $\gamma-\mathrm{Al}_{2} \mathrm{O}_{3}$ in aqueous media. Catalysis Communications 57: 23-28.

[14] Zhao, M., Shi, J., Hou, Z. (2016). Selective hydrogenation of phenol to cyclohexanone in water over $\mathrm{Pd}$ catalysts supported on Amberlyst-45. Chinese Journal of Catalysis 37(2): 234-239.

[15] Liu, H., Jiang, T., Han, B., Liang, S., Zhou, Y. (2009). Selective Phenol Hydrogenation to Cyclohexanone Over a Dual Supported Pd-
Lewis Acid Catalyst. Science 326(5957): 12501252.

[16] Ratanathavorn, W., Samart, C., Reubroycharoen, P. (2015). Tinospora crispalike ZSM-5/silica fibers synthesized by electrospinning and hydrothermal method. Materials Letters 159: 135-137.

[17] Amorim, C., Keane, M.A. (2012). Catalytic hydrodechlorination of chloroaromatic gas streams promoted by $\mathrm{Pd}$ and $\mathrm{Ni}$ : The role of hydrogen spillover. Journal of Hazardous Materials 211-212: 208-217.

[18] Fessi, S., Mamede, A.S., Ghorbel, A., Rives, A. (2012). Sol-gel synthesis combined with solid-solid exchange method, a new alternative process to prepare improved $\mathrm{Pd} / \mathrm{SiO}_{2}-\mathrm{Al}_{2} \mathrm{O}_{3}$ catalysts for methane combustion. Catalysis Communications 27: 109-113.

[19] Zheng, J., Guo, M., Song, C. (2008). Characterization of $\mathrm{Pd}$ catalysts supported on USY zeolites with different $\mathrm{SiO}_{2} / \mathrm{Al}_{2} \mathrm{O}_{3}$ ratios for the hydrogenation of naphthalene in the presence of benzothiophene. Fuel Processing Technology 89(4): 467-474.

[20] Dixit, M., Mishra, M., Joshi, P.A., Shah, D.O. (2013). Physico-chemical and catalytic properties of $\mathrm{Mg}-\mathrm{Al}$ hydrotalcite and $\mathrm{Mg}-\mathrm{Al}$ mixed oxide supported copper catalysts. Journal of Industrial and Engineering Chemistry 19(2): 458-468.

[21] Kuśtrowski, P., Sułkowska, D., Chmielarz, L., Rafalska-Łasocha, A., Dudek, B., Dziembaj, R. (2005). Influence of thermal treatment conditions on the activity of hydrotalcitederived $\mathrm{Mg}-\mathrm{Al}$ oxides in the aldol condensation of acetone. Microporous and Mesoporous Materials 78(1): 11-22.

[22] Lónyi, F., Valyon, J. (2001). On the interpretation of the $\mathrm{NH}_{3}$-TPD patterns of $\mathrm{H}$ ZSM-5 and H-mordenite. Microporous and Mesoporous Materials 47(2-3): 293-301.

[23] Rodríguez-González, L., Rodríguez-Castellón, E., Jiménez-López, A., Simon, U. (2008). Correlation of TPD and impedance measurements on the desorption of $\mathrm{NH}_{3}$ from zeolite H-ZSM-5. Solid State Ionics 179(3536): 1968-1973.

[24] Chen, J., Tian, S., Lu, J., Xiong, Y. (2015). Catalytic performance of $\mathrm{MgO}$ with different exposed crystal facets towards the ozonation of 4-chlorophenol. Applied Catalysis A: General 506: 118-125.

[25] Scirè, S., Minicò, S., Crisafulli, C. (2002). Selective hydrogenation of phenol to cyclohexanone over supported $\mathrm{Pd}$ and $\mathrm{Pd}-\mathrm{Ca}$ catalysts: an investigation on the influence of different supports and Pd precursors. Applied Catalysis A: General 235(1): 21-31. 
[26] Zhang, J., Huang, G., Zhang, C., He, Q., Huang, C., Yang, X., Song, H., Liang, Z., Du, L., Liao, S. (2013). Immobilization of highly active $\mathrm{Pd}$ nano-catalysts on functionalized mesoporous silica supports using mercapto groups as anchoring sites and their catalytic performance for phenol hydrogenation. Chinese Journal of Catalysis 34(8): 15191526.
[27] Pérez, Y., Fajardo, M., Corma, A. (2011). Highly selective palladium supported catalyst for hydrogenation of phenol in aqueous phase. Catalysis Communications 12(12): 1071-1074.

[28] Velu, S., Kapoor, M. P., Inagaki, S., Suzuki, K. (2003). Vapor phase hydrogenation of phenol over palladium supported on mesoporous $\mathrm{CeO}_{2}$ and $\mathrm{ZrO}_{2}$. Applied Catalysis A: General 245(2): 317-331. 